\title{
O uso da Hidroxicloroquina no decorrer da pandemia da COVID-19: um estudo de revisão bibliográfica
}

The use of Hydroxychloroquine during the COVID-19 pandemic: a literature review study

El uso de Hidroxicloroquina durante la pandemia de COVID-19: un estudio de revisión de la

\section{literatura}

Recebido: 05/08/2021 | Revisado: 10/08/2021 | Aceito: 11/08/2021 | Publicado: 15/08/2021

Amanda Brito Silva

ORCID: https://orcid.org/0000-0002-9884-2219

Universidade Estácio de Sá, Brasil

E-mail: brito95amanda@gmail.com

Beatriz Bonfadini de Sá Galbraith

ORCID: https://orcid.org/0000-0003-1962-9549

Universidade Estácio de Sá, Brasil

E-mail: biabgalbraith@gmail.com

Camila Lopes Rieke Borges

ORCID: https://orcid.org/0000-0003-3183-9055

Universidade Estácio de Sá, Brasil

E-mail: camilarieke@gmail.com

Daniel Pereira de Rezende Sarmento Costa

ORCID: https://orcid.org/0000-0002-7188-7142

Universidade Estácio de Sá, Brasil

E-mail: danielpereira245@yahoo.com

Danilo Bines

ORCID: https://orcid.org/0000-0002-1576-1326

Universidade Estácio de Sá, Brasil

E-mail: binesdanilo@gmail.com

Gabriela Carreiro Kubitschek Lopes ORCID: https://orcid.org/0000-0002-3984-2040

Universidade Estácio de Sá, Brasil

E-mail: gabriela.klopes97@gmail.com

Hannah Barboza Vianna Bekierman

ORCID: https://orcid.org/0000-0003-0363-1329

Universidade Estácio de Sá, Brasil

E-mail:hannahbekierman@gmail.com

Helena Ferreira Bruzzi Porto

ORCID: https://orcid.org/0000-0002-2737-7743

Universidade Estácio de Sá, Brasil

E-mail: porto.helena.bruzzi@gmail.com

Júlia Moraes de Andrade Seabra

ORCID: https://orcid.org/0000-0003-3712-9484

Universidade Estácio de Sá, Brasil

E-mail: juliamdaseabra@gmail.com

Julia Vieira Santos

ORCID: https://orcid.org/0000-0003-4549-4385

Universidade Estácio de Sá, Brasil

E-mail: juliavieirasantos98@gmail.com

Michel Vladimir de Sousa Cabral

ORCID: https://orcid.org/0000-0003-4439-522X

Universidade Estácio de Sá, Brasil

E-mail: cabralmvsc@gmail.com

Pedro Henrique Saugo

ORCID: https://orcid.org/0000-0002-1622-9251

Universidade Estácio de Sá, Brasil

E-mail: peedro.saugo@gmail.com

Victor Gonçalves de Andrade

ORCID: https://orcid.org/0000-0002-0447-7290

Universidade Estácio de Sá, Brasil

E-mail: victor23.andrade@gmail.com

Pedro Leite Azevedo

ORCID: https://orcid.org/0000-0001-7144-6032

Universidade Estácio de Sá, Brasil

E-mail: pedro.azevedo01@ @otmail.com 


\begin{abstract}
Resumo
A COVID-19 é uma doença infecciosa causada pelo SARS-CoV-2, apresenta elevada taxa de transmissão e têm resultado em milhares de óbitos registrados em todo o mundo. Atualmente, ainda não existem estudos clínicos que comprovem a eficácia de medicamentos específicos contra o SARS-Cov-2. No entanto, experiências anteriores com vírus semelhantes indicaram potencial de efetividade para determinados fármacos, dentre eles, o uso da Hidroxicloroquina (HCQ). No início da pandemia da COVID-19, a Organização Mundial da Saúde e o Ministério da Saúde orientaram a utilização da HCQ como opção terapêutica. No entanto, não se conhecia exatamente o seu papel na infecção viral pelo SARS-CoV-2, além dos seus reais benefícios in vivo. Portanto, o objetivo deste estudo foi realizar uma revisão bibliográfica sobre o uso da HCQ em casos de COVID-19, e discutir os resultados encontrados nos trabalhos que realizaram testes in vitro e in vivo, a fim de investigar a sua eficácia terapêutica. A revisão foi realizada utilizando descritores em base de dados informatizados. A eficácia antiviral da HCQ contra o SARS-CoV-2 in vitro foi descrita por diversos autores, inibindo a replicação do vírus e mediando a tempestade de citocinas por meio de seus efeitos imunomoduladores. No entanto, análises in vivo em organismos complexos não evidenciaram efeito na redução da carga viral, bem como nenhum benefício clínico ao paciente. Desta forma, apesar dos resultados preliminares in vitro terem se mostrado positivos e promissores, as evidências de ensaios clínicos randomizados apontaram que a HCQ não provocou os mesmos efeitos in vivo contra a COVID-19.
\end{abstract}

Palavras-chave: COVID-19; SARS-CoV-2; Hidroxicloroquina.

\begin{abstract}
COVID-19 is an infectious disease caused by SARS-CoV-2, has a high transmission rate and has resulted in thousands of registered deaths worldwide. Currently, there are no clinical studies proving the effectiveness of specific drugs against SARS-Cov-2. However, previous experiences with similar viruses indicated potential effectiveness for certain drugs, including the use of Hydroxychloroquine (HCQ). At the beginning of the COVID-19 pandemic, the World Health Organization and the Ministry of Health of Brazil guided the use of HCQ as a therapeutic option. However, its role in viral infection by SARS-CoV-2, in addition to its real benefits in vivo, was unknown. Therefore, the aim of this study was to conduct a literature review on the use of HCQ in cases of COVID-19, and to discuss the results found in studies that performed in vitro and in vivo tests, in order to investigate its therapeutic efficacy. The review was carried out using descriptors in a computerized database. The antiviral efficacy of HCQ against SARS$\mathrm{CoV}-2$ in vitro has been described by several authors, inhibiting virus replication and mediating cytokine storm through its immunomodulatory effects. However, in vivo analyzes in complex organisms showed no effect on reducing viral load, as well as no clinical benefit to the patient. Thus, although preliminary in vitro results have shown to be positive and promising, evidence from randomized clinical trials indicated that HCQ did not cause the same effects in vivo against COVID-19.
\end{abstract}

Keywords: COVID-19; SARS-CoV-2; Hydroxychloroquine.

\begin{abstract}
Resumen
COVID-19 es una enfermedad infecciosa causada por el SARS-CoV-2, tiene una alta tasa de transmisión y ha provocado miles de muertes registradas en todo el mundo. Actualmente, no hay estudios clínicos que demuestren la efectividad de medicamentos específicos contra el SARS-Cov-2. Sin embargo, experiencias previas con virus similares indicaron una potencial efectividad de ciertos medicamentos, incluido el uso de hidroxicloroquina (HCQ). Al comienzo de la pandemia de COVID-19, la Organización Mundial de la Salud y el Ministerio de Salud del Brazil orientaron el uso de HCQ como opción terapéutica. Sin embargo, se desconocía su papel en la infección viral por SARS-CoV-2, además de sus beneficios reales in vivo. Por lo tanto, el objetivo de este estudio fue realizar una revisión de la literatura sobre el uso de HCQ en casos de COVID-19, y discutir los resultados encontrados en estudios que realizaron pruebas in vitro e in vivo, con el fin de investigar su eficacia terapéutica. La revisión se realizó mediante descriptores en una base de datos informatizada. Varios autores han descrito la eficacia antiviral de la HCQ contra el SARS-CoV-2 in vitro, inhibiendo la replicación del virus y mediando la tormenta de citocinas a través de sus efectos inmunomoduladores. Sin embargo, los análisis in vivo en organismos complejos no mostraron ningún efecto sobre la reducción de la carga viral, así como ningún beneficio clínico para el paciente. Por lo tanto, aunque los resultados preliminares in vitro han demostrado ser positivos y prometedores, la evidencia de los ensayos clínicos aleatorios indicó que el HCQ no causó los mismos efectos in vivo contra COVID-19.
\end{abstract}

Palabras clave: COVID-19; SARS-CoV-2; Hidroxicloroquina.

\title{
1. Introdução
}

\section{COVID-19}

De acordo com a definição da Organização Mundial de Saúde (OMS), a COVID-19 é uma doença infecciosa causada por uma cepa do coronavírus recém-descoberto. Os primeiros Coronavírus foram isolados em 1937 e foram assim denominados por apresentarem uma morfologia em formato de coroa (no latim "corona" significa "coroa"), observada através 
da análise microscópica em 1965 (Lima, 2020).

Dentro da família taxonômica Coronaviridae, algumas espécies já foram associadas a infecções em humanos, como é o caso do SARS-CoV-1 e do MERS-CoV. Segundo a OMS, o coronavírus relacionado à Síndrome Respiratória Aguda Grave (SARS-CoV-1, do inglês Severe Acute Respiratory Syndrome Coronavirus 1) foi transmitido por gatos selvagens para humanos na China, em 2002. Já o correlacionado com a Síndrome Respiratória do Oriente Médio (MERS-CoV, do inglês Middle East Respiratory Syndrome Coronavirus) foi transmitido pelos dromedários para humanos na Arábia Saudita, em 2012. No entanto, também são de conhecimento científico outras espécies, dentre elas, o Alfa coronavírus 229E, Alfa coronavírus VNL 63, Beta coronavírus OC43 e o CoV-HKU1 (Lima, 2020).

Em dezembro de 2019, um grupo de pessoas foi infectado por um vírus, até então desconhecido, associado à família dos coronavírus, e apresentou sintomas associados a quadros de pneumonia. A maior parte destes indivíduos foram, provavelmente, expostos ao vírus em um mercado na cidade de Wuhan, na China, que comercializa frutos do mar e animais vivos. O aumento do número de casos de pneumonia no país chamou a atenção das autoridades sanitárias. As investigações realizadas identificaram que a causa desse quadro foi um vírus, inicialmente denominado pela OMS como o novo coronavírus 2019 (2019-nCoV), que posteriormente passou a ser chamado SARS-CoV-2 (do inglês, Severe Acute Respiratory Syndrome Coronavirus 2), responsável por causar a doença COVID-19 (Lima, 2020).

Desde a confirmação do primeiro caso de COVID-19 como uma nova cepa do gênero Coronavírus no dia 31 de dezembro de 2019 na China, houve um crescimento exponencial de infecções, devido primariamente à sua forma de transmissão, que ocorre por aerossóis e gotículas de água, sendo também facilitado pela densidade populacional nas metrópoles modernas (Organização Pan-Americana da Saúde, 2020).

O primeiro caso de COVID-19 no Brasil foi confirmado em 26 de fevereiro de 2020. Em menos de um mês após a confirmação desse caso, já havia transmissão acelerada em diversas cidades. O primeiro óbito por COVID-19 ocorreu no dia 17 de março de 2020, e, no dia 20 de março do mesmo ano, foi reconhecida a transmissão comunitária da COVID-19 em todo o Brasil (Oliveira et al., 2020).

Depois que a doença foi inicialmente notificada, houve uma elevada taxa de transmissão em um curto espaço de tempo, resultando em nove mil óbitos registrados em menos de dois meses. No entanto, esses dados são arbitrários, uma vez que se referem apenas aqueles indivíduos que realizaram o teste diagnóstico para SARS-CoV-2 e obtiveram resultado positivo. Para tentar uma aproximação do número verdadeiro de óbitos no país, foram identificados óbitos com menção à pneumonia, à septicemia e à síndrome respiratória aguda (SRAG) (Oliveira et al., 2020). No Brasil, somente no dia 06 de abril de 2020, foram notificados 926 casos de COVID-19, totalizando 12.056 casos de COVID-19 acumulados, o que representou um incremento de $8 \%$ em relação ao total acumulado até o dia anterior (Fiocruz, 2021).

Mundialmente, até o dia 05 de agosto de 2021, foram confirmados 200.174.883 casos acumulados de COVID-19, 4.255.892 mortes, apresentando uma taxa de letalidade de 2,12\% (COVID19-WHO,2021). No Brasil, no mesmo dia, foram anunciados 20.026.533 de casos confirmados acumulados por data de notificação, contabilizando 559.607 mortes acumuladas pelo novo vírus (Ministério da Saúde, 2021).

\section{Mecanismos de Ação do SARS-CoV-2 e Resposta do Hospedeiro}

$\mathrm{O}$ avanço progressivo da disseminação do SARS-CoV-2 e sua alta taxa de transmissibilidade podem também estar relacionado aos mecanismos de ação do vírus, que usa como porta de entrada celular a enzima conversora de angiotensina II (ACE2), encontrada principalmente no trato respiratório inferior humano (Jia et al., 2005).

Em uma tentativa de simular a infecção pulmonar que ocorre na COVID-19, foi avaliado um modelo de infecção por SARS-CoV-2 em camundongos K18-hACE2 via inoculação intranasal. Foi possível observar altos níveis de infecção viral nos 
pulmões desses animais com disseminação para diversos órgãos, associado a declínio da função pulmonar e presença de infiltrado inflamatório composto de monócitos, neutrófilos e células $\mathrm{T}$ ativadas, dando ênfase a uma significativa resposta imune inata do hospedeiro (Winkler et al., 2020).

Após a entrada do vírus pelo trato respiratório humano, foi observado que a glicoproteína S do SARS-CoV-2 possui duas subunidades que contribuem para a determinação do alcance do tropismo celular do vírus à célula hospedeira e atuam na fusão das membranas que permitem a entrada do RNA viral no citoplasma das células (Xia et al., 2020). Após o reconhecimento do RNA viral pelas células de defesa do hospedeiro, são ativados fatores de sinalização que levam à ativação do fator de transcrição NF-kB e o IRF3 (fator regulador de interferon), além de induzir a produção de IFN $\alpha / \beta$ e de diversas citocinas pró-inflamatórias (Kawai \& Akira, 2010).

A extensa inflamação causada pela infecção é também denominada como tempestade de citocinas ou hipercitocinemia, as quais podem acarretar no aumento da permeabilidade vascular, falência múltipla de órgãos e, eventualmente, a morte quando as concentrações de citocinas não diminuem com o tempo (Jose \& Manuel, 2020). Esse quadro é semelhante à doença Linfohistiocitose hemofagocítica, a qual apresenta uma síndrome hiperinflamatória caracterizada por uma fulminante e fatal hipercitocinemia com falência de múltiplos órgãos (Mehta et al., 2020).

No entanto, após a infecção do SARS-CoV-2, a doença pode cursar de forma sintomática ou assintomática. Apresenta-se como sinais e sintomas iniciais um quadro que se assemelha ao de uma gripe comum, podendo evoluir para hipercitocinemia, pneumonia grave e Síndrome Respiratória Aguda Grave (SRAG) com pelo menos dois dos seguintes sintomas: sensação febril ou febre associada a dor de garganta, dor de cabeça, tosse e coriza. Entretanto, a maioria dos infectados apresenta a forma leve da doença com bom prognóstico. Os sintomas mais comuns observados nos pacientes são: febre, fadiga, tosse, dor de garganta, dispneia leve, dor de cabeça, dor no corpo, dificuldade de respirar, anosmia, hiposmia e ageusia (Iser et al., 2020; Xavier et al., 2020).

Um estudo brasileiro realizado pelo Instituto Israelita de Ensino e Pesquisa Albert Einstein com 510 pacientes diagnosticados com COVID-19 evidenciou que 20,2\% dos pacientes apresentavam pelo menos uma comorbidade. Além disso, foi observado um aumento de 15,25\% para 50\% da presença de comorbidades entre o grupo hospitalizado quando comparado ao grupo dos indivíduos não hospitalizados (Iser et al., 2020).

As comorbidades relacionadas ao maior risco de internação são as doenças crônicas pré-existentes, como a doença renal crônica, doenças cardíacas, obesidade, diabetes, hipertensão e asma. Além disso, pessoas idosas e pacientes imunocomprometidos também podem apresentar pior prognóstico. No entanto, vale ressaltar que, quando se tem duas ou mais comorbidades, o risco aumenta. Diante disso, uma pessoa que possui duas dessas condições supracitadas apresenta 4,5 vezes mais risco de ser hospitalizado. A presença de 3 ou mais dessas condições apresenta 5 vezes mais chances de hospitalização (Ko et al., 2020).

Iser e colaboradores evidenciaram que, dentre os pacientes diagnosticados com o SARS-CoV-2, $14 \%$ dos pacientes foram hospitalizados, dentre os quais, $27,8 \%$ necessitavam de cuidados intensivos, $44,4 \%$ precisaram de oxigenoterapia e $23,6 \%$ de ventilação mecânica. Durante a internação, 58,3\% dos pacientes foram diagnosticados com pneumonia; 9,7\% com lesão renal aguda; e 8,3\%, com SDRA (Iser et al., 2020).

Considerando os pacientes que necessitavam de cuidados intensivos, o tempo médio de internação foi de 9 dias; o de permanência na UTI, de 15,25 dias; e o total de internação, de 22 dias. Em relação aos pacientes que não precisaram de UTI, o tempo médio de internação foi de 7 dias. Nesse estudo, constatou-se somente um óbito que representou uma taxa de mortalidade de $1,38 \%$. No entanto, o estudo incluiu apenas pacientes atendidos ambulatorialmente ou internados e não foram considerados casos assintomáticos e leves que não procuraram assistência médica (Iser et al., 2020). 


\section{Terapia Farmacológica}

Embora testes diagnósticos tenham sua sensibilidade e especificidade bem documentadas, não há estudos clínicos de larga escala que comprovem a eficácia de medicamentos contra o SARS-Cov-2. No entanto, experiências anteriores com vírus semelhantes, além de diversos trabalhos publicados até a confecção desse estudo, indicam potencial de efetividade para determinados fármacos, analisados a seguir (Andrade et al., 2020).

O Remdesivir obteve sucesso no combate ao vírus SARS-Cov-2 in vitro e também contra outros coronavírus em modelos animais (Wang et al., 2020). Esse antiviral tem como mecanismo a inibição da polimerase de RNA dependente de RNA viral (RdRp) enquanto inibe a exoribonuclease 17, o que resulta na terminação prematura da transcrição viral de RNA (Agostini et al., 2018). Apesar de seu sucesso em testes in vitro e em testes em humanos no tratamento da COVID-19, preocupações permanecem em relação à eficácia clínica e à recorrência de efeitos adversos mediantes seu uso (Martinez, 2020).

O Favipiravir é um derivado da pirazina carboxamida que inibe seletivamente a RNA polimerase dependente do RNA viral da influenza, bloqueando assim o processo de replicação, ao agir negativamente na cópia genética. Devido à sua atividade contra vírus RNA, esse medicamento foi testado contra vários vírus RNA, incluindo H1N1 e Ebola. Esse antiviral tem como alvo as enzimas RNA polimerase dependentes de RNA (RdRp), necessárias para a transcrição e replicação de genomas virais, e se mostrou eficaz contra os subtipos e cepas do H1N1, incluindo aquelas sensíveis ou resistentes à neuraminidase e a inibidores M2 (Chen et al., 2020; Furuta et al., 2017).

A Ribavirina é um medicamento antiviral análogo à guanosina e têm sido usado para tratar várias infecções virais, incluindo o vírus da hepatite $\mathrm{C}$, vírus sincicial respiratório e alguns vírus de febres hemorrágicas. Testes com a presença de Ribavirina têm sido realizados, porém seus efeitos adversos, que incluem a redução de hemoglobina, comprometem seu potencial benéfico (Martinez, 2020).

A associação de Lopinavir/Ritonavir (LPV / RTV), ambos inibidores de proteases, são importantes para o tratamento crônico do HIV e foram testados para o tratamento de SARS-Cov-2. No entanto, em um estudo aberto e randomizado envolvendo 199 pacientes hospitalizados, a adição de LPV/RTV para tratamento padrão não resultou em melhora clínica mais rápida ou uma redução acelerada dos níveis de RNA de SARS-CoV-2 (Furuta et al., 2017). Apesar dos resultados desanimadores, um número ligeiramente menor de mortes foi observado no grupo que recebeu LPV/RTV no estágio final da infecção por SARS-CoV-2 em comparação com o grupo de tratamento padrão (Sheahan et al., 2020).

A Dexametasona é um corticosteroide usado em diferentes condições devido à sua ação anti-inflamatória e imunossupressora. A utilização de $6 \mathrm{mg} /$ dia de dexametasona resultou em uma redução absoluta na mortalidade de $2,8 \%$ (22,9\% vs 25,7\% para o tratamento usual). O benefício foi maior para os pacientes que estavam recebendo ventilação mecânica invasiva no momento da randomização com mortalidade de $29,3 \%$ para dexametasona contra $41,4 \%$ para o tratamento usual (World Health Organization, 2021). Em pacientes criticamente enfermos com COVID-19, a administração de corticosteroides sistêmicos, em comparação com o tratamento usual ou placebo, foi associada à menor mortalidade por todas as causas em 28 dias. O relatório publicado pela OMS recomenda a não utilização dessa classe de fármacos para pacientes não graves (World Health Organization, 2021).

A Ivermectina é um antiparasitário de largo espectro, com ação também contra diferentes vírus in vitro. Para testar sua eficácia contra o SARS-CoV-2, células infectadas com o vírus foram tratadas com ivermectina 2 horas após a exposição, sendo constatada redução de até 500 vezes do RNA viral em 48 horas. A droga pode ter efeitos antivirais ao inibir o receptor $\alpha / \beta$ importina (IMP), que é responsável pela transmissão de proteínas virais para o núcleo da célula hospedeira (Caly et al., 2020).

A Azitromicina é um fármaco da classe dos macrolídeos comumente usada para infecções respiratórias bacterianas e pode potencialmente tratar ou prevenir a infecção por SARS-CoV-2 (Retallack et al., 2016). A atividade antimicrobiana dos 
macrolídeos resulta da inibição da síntese de proteínas bacterianas por meio da ligação reversível ao túnel de saída do peptídeo dos ribossomos. Além de sua ação antibiótica, a azitromicina também pode exercer atividade imunomodulatória (Zimmermann et al., 2018). Em um estudo brasileiro em pacientes com COVID-19 grave, publicado em setembro de 2020, a adição de azitromicina ao tratamento padrão (que incluía hidroxicloroquina) não melhorou os resultados clínicos (Furtado et al., 2020).

Além desses fármacos, muitos trabalhos evidenciaram a utilização da Cloroquina e da Hidroxicloroquina para o tratamento da COVID-19, baseados em resultados que identificaram a eficácia in vitro desses medicamentos direcionados ao SARS-CoV-2 (Keyaerts et al., 2004). No início da pandemia, a própria OMS, o Ministério da Saúde e diversos hospitais implantaram a utilização da Cloroquina como opção terapêutica para a COVID (Ministério da Saúde, 2020). No entanto, não se conhecia exatamente o papel desses medicamentos na infecção viral pelo SARS-CoV-2, além dos seus reais benefícios in vivo. Portanto, o objetivo deste estudo foi realizar uma revisão bibliográfica da literatura sobre o uso de Hidroxicloroquina em casos de COVID-19, analisando seu desempenho in vitro e in vivo, a fim de investigar a eficácia da terapia farmacológica proposta.

\section{Metodologia}

Neste estudo, foi realizada uma análise descritiva exploratória a partir de um banco de dados virtual (Estrela, 2018; Pereira et al., 2018). Essa revisão bibliográfica foi realizada utilizando como descritores: "hidroxicloroquina", "hidroxicloroquina in vitro", "hidroxicloroquina in vivo", "exame radiológico na COVID-19", "histórico da COVID-19, "Coronavírus", "sinais e sintomas da COVID-19", "Manifestações clínicas COVID-19”, "COVID-19 no Brasil”, "óbitos por COVID-19", “epidemiologia da COVID-19", “COVID-19”, "COVID”, "hydroxychloroquine”, "guideline pharmaceutical treatment", "epidemiology COVID-19", "comorbidities that increase the chance of coronavirus", "Treatments for COVID-19", "hydroxicloroquin associated with azitromicin". Em algumas situações, esses descritores foram utilizados em associação. A busca destes descritores foi realizada na base de dados informatizados MEDLINE, SciELO, Fiocruz, PubMed, BVS, BMJ, Oxford, medRxiv e em sites oficiais da OMS e do CDC (do inglês, Centers for Disease Control and Prevention) com trabalhos publicados até o mês de novembro de 2020. A partir da coleta de dados, foi possível selecionar 88 artigos científicos. Com base nos artigos encontrados, foram selecionados os de maior relevância para o objetivo do estudo, os quais evidenciaram informações com relação ao uso histórico do medicamento (comparação com uso de cloroquina), seu mecanismo de ação, propriedades farmacocinéticas, farmacodinâmicas, além dos testes in vitro, in vivo, e seus resultados clínicos e laboratoriais relacionados com à pandemia de COVID-19.

\section{Resultados e Discussão}

\section{Histórico e Propriedades farmacológicas da Hidroxicloroquina}

A Hidroxicloroquina (HCQ) pertence a um grupo de medicamentos antimaláricos amplamente utilizados para sua quimioprofilaxia e tratamento (Brunton et al., 2019). O primeiro uso da quinina como medicamento é tradicionalmente atribuído aos descendentes incas no Peru em 1630, tendo origem na casca de árvores Cinchona nativas de áreas montanhosas da América Latina (Mates et al., 2007).

Na década de 1940, como parte do extenso programa cooperativo de pesquisa antimalárica nos Estados Unidos durante a Segunda Guerra Mundial, a Cloroquina foi um dos compostos sintetizados e avaliados. Nesse período, milhões de soldados fizeram a profilaxia antimalárica e foi observada uma melhora em erupções cutâneas e na artrite inflamatória. Desde então, a Cloroquina tem sido utilizada no tratamento de doenças reumáticas (Page, 1951). A forma sintética, Hidroxicloroquina, foi introduzida em 1955 (Ben-Zvi et al., 2012).

Tanto a Hidroxicloroquina quanto a Cloroquina pertencem a uma classe de drogas conhecidas como 4- 
aminoquinolinas (Manohar et al., 2014) . Ambas possuem uma estrutura central aromática plana semelhantes e são bases fracas. Além disso, apresentam grande distribuição de volume e meia-vida longa, o que é consistente com seu início de ação lento e efeitos prolongados após descontinuação do medicamento (Rainsford et al., 2015).

A Hidroxicloroquina é administrada como um sulfato, enquanto a Cloroquina é administrada como um fosfato de sal, porém ambas são geralmente absorvidas na parte superior do trato intestinal (Tett et al., 1989). A Hidroxicloroquina difere da Cloroquina por possuir um grupo hidroxila a mais, o que pode estar relacionado a uma menor toxicidade (Ben-Zvi et al., 2012).

Observações clínicas sugerem que a Hidroxicloroquina está associada a um risco menor de retinopatia do que a Cloroquina, o que pode ser possivelmente explicado pelo seu menor volume de distribuição (Rynes \& Bernstein, 1993). Além disso, o uso da Hidroxicloroquina apresenta menor potencial para interações medicamentosas adversas do que a cloroquina in vitro (Yao et al., 2020).

A Hidroxicloroquina é uma droga ativamente utilizada em doenças autoimunes (como artrite reumatoide e lúpus eritematoso) (Cortegiani et al., 2020). Muitos autores tentam explicar os efeitos farmacológicos da HCQ. No entanto, a maioria dos modelos utilizados são baseados em estudos in vitro. Tal como outros medicamentos, o mecanismo de ação desse fármaco depende das condições inflamatórias e / ou dos tecidos ou órgãos afetados (Schrezenmeier \& Dörner, 2020).

Já foram descritos na literatura alguns mecanismos celulares da HCQ, nos quais diversos autores documentaram que tanto a Hidroxicloroquina, quanto a Cloroquina interferem em mecanismos lisossomais. Evidências demonstram que essas drogas se acumulam no interior dos lisossomos, sendo capazes de elevar o pH e inibir a função deles, que são essenciais para a fusão do vírus com a célula (Mauthe et al., 2018).

A inibição da atividade lisossomal induzida pela HCQ pode afetar o processamento de antígenos através do MHC II e, dessa forma, causar a inibição da ação de linfócitos, demonstrando assim efeito imunomodulatório (Schrezenmeier \& Dörner, 2020).

Além destes efeitos, a HCQ interfere inibindo a fagocitose, a proteólise, a quimiotaxia, a produção de citocinas por macrófagos, especialmente IL-1 e IL-6, e a sinalização de canais de $\mathrm{Ca}^{+}$em linfócitos B e T (Goldman et al., 2000). Esse fármaco também inibe a fosfolipase A2 e antagoniza os efeitos das prostaglandinas. Nesse contexto, também é reconhecida por interferir em receptores toll like, como TLR7 e TLR9, e na atividade da GMP-AMP cíclica (cGAMP) sintase (cGAS) (Zhang et al., 2014). Os efeitos da HCQ culminam em uma inibição da sinalização pró-inflamatória e a produção de citocinas, atuando como imunomoduladores.

A HCQ demonstrou ser eficaz contra infecções bacterianas e virais, devido ao efeito de alcalinização da droga em organelas intracelulares (lisossomos) de células infectadas (Rolain et al., 2007). Mostrou também ser capaz de auxiliar na redução de taxas de aterosclerose, no controle glicêmico e na redução da hiperlipidemia (Rempenault et al., 2018), contribuindo para o tratamento de doenças cardiovasculares. Seu efeito antitrombótico foi observado através de um mecanismo ainda não totalmente esclarecido, mas parece inibir agregação plaquetária e produção de ácido araquidônico por plaquetas ativadas (Nosál et al., 1995).

Ademais, o fármaco demonstrou induzir a apoptose de células B malignas em pacientes com leucemia (Lagneaux et al., 2001). Recentemente, esse medicamento demonstrou ter efeito pró-apoptótico em células derivadas de pacientes com leucemia linfocítica crônica (LLC) de células B in vitro (Mansilla et al., 2010), assim como efeito antineoplásico em tumores sólidos (Zhou et al., 2002).

A atividade do sulfato de Hidroxicloroquina in vitro foi amplamente documentada contra viroses, surgindo como um possível composto ativo contra o SARS-CoV-2 (Rolain et al., 2007). Conforme já abordado, a droga diminui o nível de citocinas inflamatórias que podem ser relevantes na infecção pelo COVID-19 (Schrezenmeier \& Dörner, 2020). 
Esses antimaláricos podem causar alguns efeitos adversos. A toxicidade da hidroxicloroquina pode se manifestar em efeitos cardiovasculares como hipotensão, vasodilatação, função do miocárdio suprimida e arritmias cardíacas. Todavia, no sistema nervoso central, a toxicidade da hidroxicloroquina pode se apresentar com convulsões, confusão e até mesmo coma.

Além disso, o uso prolongado da HCQ pode causar visão turva, confusão, irregularidades no intervalo QRS, diplopia, descoloração das unhas e mucosas membranosas. Retinopatia e ototoxicidade podem ser resultado de doses elevadas (Bortoli \& Santiago, 2007; Wolfe \& Marmor, 2010). O seu uso também pode resultar em efeitos adversos nos sistemas hematológico, renal e hepático (Cortegiani et al., 2020).

Baseados nestes efeitos farmacológicos da Hidroxicloroquina e da Cloroquina, diversos pesquisadores propuseram que o seu uso poderia ser benéfico para tratar os pacientes infectados com o SARS-CoV-2, uma vez que o fármaco poderia atuar nos mecanismos virais descritos no item 1.2. da introdução e inibir a sua replicação.

Sob esse prisma, a utilização empírica destes fármacos foi favorecida, visto que já são amplamente disponíveis no mercado e possuem propriedades bem estabelecidas na literatura, de forma que era possível atender a demanda pelo medicamento no momento de pandemia.

\section{Ensaios in vitro da Hidroxicloroquina e o SARS-CoV-2.}

No início de março de 2020, Yao e colaboradores publicaram resultados de um ensaio antiviral utilizando linhagens de células Vero E6 derivadas dos rins de macacos verdes africanos infectadas com SARS-CoV-2. O estudo teve como o objetivo investigar a atividade antiviral e profilática da hidroxicloroquina e cloroquina in vitro, construir um modelo PBPK (do inglês Physiologically based pharmacokinetic modeling, é uma técnica de modelagem matemática para prever a absorção, distribuição, metabolismo e excreção de substâncias químicas sintéticas ou naturais em humanos e outras espécies animais) para hidroxicloroquina e cloroquina usando dados da literatura e prever as concentrações da droga em diferentes regimes de dosagem (Yao et al., 2020)(Yao et al., 2020).

Os estudos in vitro são conduzidos usando componentes de um organismo que foram isolados de seu ambiente biológico usual, como microrganismos, células ou moléculas biológicas. Eles podem ser estudados em meios de cultura artificiais e examinados em soluções. São tradicionalmente feitos em tubos de ensaio, frascos e placas de Petri. Esse método permite uma análise específica e detalhada de componentes isolados, sendo mais simples, baratos e convenientes (Kumar et al., 2020).

Yao e colaboradores dividiram os experimentos em 2 seções. A primeira seção avaliou o impacto do tratamento com os fármacos na infecção do SARS-CoV-2, no qual as células Vero foram infectadas por 2 horas e então foram tratadas em um meio contendo Cloroquina ou Hidroxicloroquina em concentrações diferentes por 24 ou 48 horas. A segunda parte do trabalho observou o impacto do uso profilático das drogas, em que as células Vero foram pré-tratadas com Cloroquina e Hidroxicloroquina durante 2 horas, em seguida elas foram removidas do meio contendo a droga, e o vírus foi adicionado às células Vero por 2 horas. Por fim, as células foram adicionadas a um meio que possuía novamente as drogas em concentrações diferentes e permaneceram incubadas por 24 ou 48 horas (Yao et al., 2020).

Este trabalho evidenciou que a Hidroxicloroquina foi mais eficaz em impedir a replicação viral, quando comparada com a eficácia da Cloroquina administrada após a infecção, com um EC50 (concentração para qual 50\% da população exibe uma resposta) de 48 horas de 0,72 $\mu \mathrm{M}$ e 5,47 $\mu \mathrm{M}$ para Hidroxicloroquina e Cloroquina, respectivamente. Demonstrou também que a Hidroxicloroquina foi mais eficaz do que a Cloroquina em impedir a replicação do vírus SARS-CoV-2 quando administrada profilaticamente; a EC50 de 48 horas para Hidroxicloroquina e Cloroquina foram 5,85 $\mu \mathrm{M}$ e 18,01 $\mu \mathrm{M}$, respectivamente (Yao et al., 2020).

Para identificar um potencial regime de drogas para uso em humanos, os modelos farmacocinéticos de base fisiológica 
(PBPK) foram empregados para considerar a rota de administração do medicamento, parâmetros fisiológicos (ou seja, absorção intestinal e penetração no tecido pulmonar) e propriedades bioquímicas do medicamento. A publicação relatou concentrações simuladas de fluido pulmonar, mas não forneceu todos os detalhes usados no modelo. $\mathrm{O}$ regime mais promissor para o tratamento de COVID-19 com base neste modelo foi uma dose inicial de $400 \mathrm{mg}$ de Hidroxicloroquina duas vezes ao dia e uma dose de manutenção de $200 \mathrm{mg}$ duas vezes ao dia durante quatro dias. Um intervalo de confiança de $95 \%$ para a estimativa de EC50 não foi fornecido e, portanto, este regime de dosagem deve ser interpretado com cautela, pois pode ser uma estimativa imprecisa (Yao et al., 2020).

É importante frisar que se notou que, com a incubação de longos períodos, o valor de EC50 tendeu a diminuir, tanto no caso da Cloroquina quanto no da Hidroxicloroquina. Esse resultado sugere que, quanto maior o período de incubação, maior é a concentração da droga da célula, devido ao seu acúmulo intracelular, o que gera um melhor efeito antiviral (Yao et al., 2020).

Com base em seus resultados, os autores chegaram à conclusão de que a Hidroxicloroquina poderia apresentar um alto potencial de tratamento contra a infecção por SARS-CoV-2, pois ela atuaria inibindo a replicação do vírus e ajudaria a mediar a tempestade de citocinas por meio de seus efeitos imunomoduladores. Baseando nessas conclusões, criou-se a recomendação do uso concomitante de Hidroxicloroquina em baixa dosagem e de um anti-inflamatório para ajudar a mitigar a tempestade de citocinas em pacientes criticamente enfermos com SARS-CoV-2 (Yao et al., 2020).

Em um outro estudo, Liu e colaboradores avaliaram o efeito do Remdesivir e do Fosfato de Cloroquina (CQ), tentando estabelecer se esses fármacos eram eficientes na inibição da infecção por SARS-CoV-2 in vitro. O estudo também avaliou o efeito antiviral da Hidroxicloroquina (HCQ) em comparação com a CQ in vitro, considerando a citotoxicidade de HCQ e CQ nas linhagens de células Vero E6 infectadas com SARS-CoV-2. A comparação da atividade antiviral da CQ versus HCQ foi baseada nas curvas de dose-resposta dos dois compostos, em que foi possível determinar quatro diferentes variações de infecção (MOIs) por quantificação de vírus (Liu et al., 2020).

Inicialmente, pensava-se no Remdesivir como medicamento promissor no tratamento da infecção por SARS-Cov-2, contudo tal medicamento não se encontrava amplamente disponível no mercado, de forma que fosse possível atender a demanda pelo medicamento durante a pandemia, quando comparada à disponibilidade da Cloroquina e da Hidroxicloroquina (Liu et al., 2020).

A partir da análise dos resultados obtidos nesse estudo in vitro, foi possível observar que a Cloroquina inibe a entrada do SARS-CoV-2 através da alteração da glicosilação do receptor ECA2 e da glicoproteína $\mathrm{S}$, bem como nos estágios pósentrada do vírus (Liu et al., 2020).

Esses medicamentos foram capazes de bloquear o transporte do vírus dos endossomos para endolisossomos, o que se mostra essencial para liberá-lo do genoma. Além disso, percebeu-se que tal tratamento provocava mudanças no número, no tamanho e na morfologia de tais organelas, enquanto, nas células não tratadas, os endossomos eram menores que os endolisossomos. A acidificação se mostra crucial para a maturação do endossoma e sua função, sendo assim, esse processo também pode ser bloqueado em estágios intermediários de endocitose, provocando a falha no transporte dos vírions na célula, uma vez que os fármacos promovem um aumento do $\mathrm{pH}$ das organelas (Liu et al., 2020).

Os autores Liu e colaboradores evidenciaram que a absorção oral de Cloroquina e Hidroxicloroquina em humanos se mostrou eficiente. Sendo que, in vivo, ambas as drogas se assemelham no padrão de distribuição, com altas concentrações no fígado, baço, rim e pulmão, atingindo níveis maiores nesses órgãos do que no plasma (Liu et al., 2020).

Outro estudo também propôs que a Azitromicina (AZTH), que mostrou apresentar efeito antiviral in vitro contra o SARS-CoV-2, poderia potencializar a eficácia da Hidroxicloroquina. Baseado nisso, a Hidroxicloroquina foi considerada para o tratamento de COVID-19, sozinha ou combinada com a Azitromicina (Maisonnasse et al., 2020). 
A eficácia antiviral da Hidroxicloroquina contra o SARS-CoV-2 in vitro também foi descrita por outros autores. Por exemplo, o tratamento das células Vero E6 infectadas com o vírus isolado dos primeiros pacientes com COVID-19 da França também resultou em um efeito antiviral dose-dependente. O estudo encontrou uma IC50 (50\% de concentração inibitória) com valores de $2.2 \mu \mathrm{M}(0.7 \mu \mathrm{g} / \mathrm{mL})$ e $4.4 \mu \mathrm{M}(1.4 \mu \mathrm{g} / \mathrm{mL})$ nas 48 e 72 horas após a infecção, respectivamente (Maisonnasse et al., 2020).

Baseados nesses resultados iniciais in vitro da Hidroxicloroquina na infecção do SARS-CoV-2, outros trabalhos foram delineados com o objetivo de certificar se esses efeitos aconteciam em organismos complexos. Por isso, outras metodologias foram utilizadas e ao mesmo tempo foram iniciados os estudos clínicos em humanos, que serão discutidos a seguir.

\section{Ensaios in vivo da Hidroxicloroquina e o SARS-CoV-2.}

Os primeiros trabalhos in vivo utilizaram macacos verdes africanos, infectados com uma dose total de $10^{6} \mathrm{PFU}$ (unidades formadoras de placas) do SARS-CoV-2 isolado. Os animais exibiram sinais clínicos, como reportado na maioria dos casos humanos durante o período inicial de infecção, incluindo tosse e espirro sem dispneia. Nenhum animal do grupo controle desenvolveu o quadro grave, semelhante ao observado inicialmente nas doenças severas em humanos. Portanto, o autor descreve que esses animais são modelos relevantes para o estudo dos estágios iniciais de infecção por SARS-CoV-2 em humanos (Maisonnasse et al., 2020).

O método utilizado para a confirmação da infecção pelo SARS-CoV-2 nos animais foi o RT-qPCR que permitiu uma comparação com os resultados encontrados em humanos. Para avaliar a eficácia do medicamento, os animais receberam Hidroxicloroquina todos os dias por 10 dias ou mais. Foram utilizada uma dose de $90 \mathrm{mg} / \mathrm{kg}$ no primeiro dia pós infecção, seguida por uma dose de manutenção de $45 \mathrm{mg} / \mathrm{kg}$. Após o tratamento com a Hidroxicloroquina, foi identificada no grupo de animais não infectados uma concentração plasmática de HCQ clinicamente relevante que poderia apresentar um potencial efeito antiviral nos animais infectados com o SARS-CoV-2 e, se confirmado o potencial antiviral, o fármaco poderia ser utilizado em casos de COVID-19 em humanos (Maisonnasse et al., 2020).

A Hidroxicloroquina não acelerou o tempo de eliminação viral (ausência de detecção viral) em animais tratados em um ou cinco dias após a infecção. No grupo controle, o tempo médio para a primeira carga viral não quantificável foi de quatro dias e 12 horas. Já para os animais que utilizaram o medicamento em baixas dosagens, em altas dosagens ou utilizaram baixas dosagens após o quinto dia de infecção, o tempo médio para a primeira carga viral não quantificável foi de sete dias. Portanto, nota-se que nem o tempo para atingir o limite de carga viral de quantificação, nem o pico de carga viral foi significantemente associado à concentração de plasma de Hidroxicloroquina (Maisonnasse et al., 2020).

Evidenciou-se nos animais que o tratamento com hidroxicloroquina não preveniu linfopenia ou lesões pulmonares, como visto na Tomografia Computadorizada (TC). Todos os animais tratados exibiram um aumento de IFN- $\alpha$, IL-1, CCL2 e CCL11 no plasma no segundo dia pós-infecção. Além disso, os resultados não mostraram nenhuma atividade antiviral ou eficiência clínica, independentemente do tempo de iniciação do tratamento, mesmo antes da infecção, como medida profilática pré-exposição, no início ou depois da infecção (antes do pico viral) ou no final da infecção (depois do pico viral). Assim, o estudo concluiu que tanto o tratamento com HCQ quanto com HCQ+AZTH não teve nenhum efeito na redução da carga viral (Maisonnasse et al., 2020).

Os resultados também evidenciaram uma discrepância entre os achados in vitro e in vivo, como mostrado por outras infecções virais, como influenza, dengue, Chikungunya, em que os processos clínicos falharam em demonstrar eficácia da Cloroquina ou da Hidroxicloroquina. A partir destes resultados e da avaliação in vivo da Hidroxicloroquina, as evidências apontavam para a não utilização deste fármaco como agente antiviral para o tratamento de COVID-19 em humanos, seja sozinha ou em combinação com Azitromicina (Maisonnasse et al., 2020). 
De fato, estudos clínicos revelaram que a utilização de Hidroxicloroquina pode não trazer diferença ou até piorar a evolução de pacientes infectados com o vírus SARS-CoV-2 (Lee et al., 2020; Skipper et al., 2020). Os achados mais relevantes até a confecção deste manuscrito serão discutidos a seguir.

No período de março a julho de 2020, durante o maior aumento de casos de COVID-19 da pandemia, grande parte da comunidade internacional persistia esperançosa com o possível uso da Hidroxicloroquina para o tratamento da COVID-19 com base em estudos seletos sobre sua eficácia descritos anteriormente (Gautret et al., 2020; Liu et al., 2020).

Gautret e colaboradores realizaram um ensaio clínico não randomizado e com uma pequena amostra em que foram avaliados 38 pacientes com COVID-19. Sendo que 20 faziam parte do grupo de intervenção para qual era administrado Hidroxicloroquina e 16 do grupo controle sem uso de placebo (Gautret et al., 2020). Portanto, esse estudo demonstrou-se suscetível a viés de aferição, o qual pode ocorrer quando os aferidores e participantes têm conhecimento acerca de quais indivíduos compõem cada grupo. Dessa forma, os participantes no grupo da intervenção tendem a direcionar seus relatos positivamente e os médicos tendem a aferir os resultados fazendo o mesmo. Ademais, o estudo também apresenta um déficit no devido acompanhamento dos pacientes.

Nesse estudo preliminar, conclui-se que a Hidroxicloroquina é efetiva na profilaxia e tratamento do COVID-19 sendo seu efeito intensificado quando ministrado em conjunto com a Azitromicina. Por outro lado, os autores enfatizam que esses resultados deveriam ser confirmados com um número maior de amostras e controles de qualidade (Gautret et al., 2020).

Em estudos feitos posteriormente ao de Gautret e colaboradores, foram descobertos resultados negativos em relação à eficácia do uso da Hidroxicloroquina in vivo. Um deles foi publicado dia 30 de setembro de 2020 (Abella et al., 2021).

Nesse ensaio, foram avaliados trabalhadores da área de saúde que tiveram contato direto com pacientes de COVID19 entre o dia 9 de abril e 14 de julho de 2020. Os participantes incluídos foram médicos, enfermeiras, técnicos de enfermagem, técnicos emergencialistas e terapeutas respiratórios que possuíam uma carga horária de, no mínimo, 20 horas de trabalho no hospital em contato direto com pacientes infectados (Abella et al., 2021).

Os 132 participantes que efetivamente participaram do estudo foram randomizados pela "Penn Investigational Drug Service" (IDS) em razão de amostra 1:1 para receberem a intervenção de Hidroxicloroquina $600 \mathrm{mg}$ diariamente ou para utilizar o placebo, sendo a randomização feita em blocos de oito. A IDS manteve a randomização oculta da equipe do estudo, dos investigadores até a intervenção analítica e dos próprios participantes, tornando o ensaio clínico duplo cego (Abella et al., 2021).

Foram realizados testes RT-PCR e sorologia testando 3 anticorpos (anti-IGG, anti-IGM e anti-RBD IGG) no momento em que a randomização foi realizada (baseline) e durante a quarta e oitava semana do estudo. Porém, aqueles que desenvolveram sintomatologia condizente com a COVID19 foram encaminhados com urgência para fazer RT-PCR independente da agenda do estudo. Posteriormente, foi adicionada uma análise da eletrocardiografia (ECG) pela preocupação de que a Hidroxicloroquina aumentaria o intervalo QT. Todos os participantes do estudo recebiam semanalmente um questionário para revisionar o diário de adesão das pílulas e um questionário de eventos adversos padronizado (Abella et al., 2021).

Nos resultados, os autores observaram que a taxa de positividade era semelhante nos pacientes que receberam a Hidroxicloroquina (6.3\%) e no grupo placebo (6.6\%), com valor $\mathrm{P}=0.99$. Nenhum dos 8 participantes com COVID demandou hospitalização, sendo todos assintomáticos ou com sintomas leves, e tiveram recuperação completa. Portanto, a equipe não detectou uma redução significativa da transmissão de SARs-CoV-2 com a administração profilática da Hidroxicloroquina, no entanto a equipe identificou mais efeitos adversos com o uso da medicação (Abella et al., 2021).

Em outro estudo, foram avaliados pacientes que sofreram previamente exposição a outro indivíduo com COVID-19. Os pacientes foram randomizados para Hidroxicloroquina ou placebo por 5 dias. Neste estudo, não foi observada nenhuma 
diferença em termos da taxa de infecções subsequentes. Além disso, o grupo da Hidroxicloroquina apresentou mais efeitos colaterais (Boulware et al., 2020).

Tang e colaboradores também observaram que, em pacientes internados com COVID-19, apresentando um quadro clínico leve a moderado, randomizados para Hidroxicloroquina ou placebo por 2-3 semanas, não houve diferença na redução da carga viral no total de 28 dias (Tang et al., 2020).

Mitja e colaboradores observaram que, em pacientes não hospitalizados, testados positivamente para o SARS-CoV-2 e com menos de cinco dias de sintomas, não foi observada diferença em termos de redução da carga viral, risco de hospitalização ou tempo de resolução dos sintomas após a randomização para Hidroxicloroquina ou placebo (Mitjà \& Clotet, 2020).

Em um estudo com adultos não hospitalizados com COVID-19 confirmado ou provável COVID-19, os pacientes foram randomizados para receber Hidroxicloroquina ou placebo por cinco dias. Também não houve diferença na gravidade geral dos sintomas ao longo de 14 dias. O grupo da Hidroxicloroquina experimentou mais efeitos colaterais (Skipper et al., 2020).

Em um artigo ainda não revisado por pares, os pacientes hospitalizados com COVID-19 foram randomizados para a utilização da Hidroxicloroquina por 10 dias ou até a alta, em comparação ao tratamento usual. Não houve diferença em relação à mortalidade de 28 dias. Outra conclusão foi que o grupo da Hidroxicloroquina apresentou um tempo maior de internação e um risco aumentado de evoluir para ventilação ou morte (LEE, et al., 2020).

Outro importante estudo em desenvolvimento, realizado em 176 hospitais no Reino Unido, apoiado pelo National Institute for Health Research Clinical Research Network, é denominado RECOVERY Trial (do inglês, Randomised Evaluation of COVID-19 Therapy). Estudo randomizado individualmente, controlado e aberto para avaliar os efeitos de potenciais tratamentos em pacientes hospitalizados com COVID19, dentre eles a Hidroxicloroquina (The RECOVERY Collaborative Group, 2020).

Esse estudo é coordenado pelo Departamento de Saúde da População de Nuffield da Universidade de Oxford. Os pacientes hospitalizados eram elegíveis para o estudo se apresentassem alguma suspeita clínica ou laboratorial confirmando a infecção por SARS-CoV-2 e nenhum histórico médico que pudesse, na opinião do médico assistente, colocar o paciente em risco significativo se ele participasse do estudo (The RECOVERY Collaborative Group, 2020).

Os pacientes elegíveis e que consentiram foram atribuídos em uma proporção de 2:1 para qualquer padrão usual de atendimento ou padrão usual de atendimento mais Hidroxicloroquina ou um dos outros braços de tratamento disponíveis usando randomização simples, não estratificada, com ocultação de alocação. Pacientes alocados para a utilização de Sulfato de Hidroxicloroquina (comprimido de $200 \mathrm{mg}$ contendo $155 \mathrm{mg}$ de base equivalente) receberam uma dose de quatro comprimidos (800 mg) à zero e seis horas, seguido por dois comprimidos (400mg) começando 12 horas após a dose inicial e, em seguida, a cada 12 horas durante nove dias ou até ausência viral (The RECOVERY Collaborative Group, 2020). Um único formulário de acompanhamento on-line deveria ser preenchido quando os participantes tivessem alta, em casos de óbitos ou após 28 dias da randomização.

Nesse estudo não foi observada uma diferença significativa na proporção de pacientes que atenderam ao desfecho primário de mortalidade de 28 dias entre os dois braços randomizados (418 [26,8\%] pacientes no braço de Hidroxicloroquina vs. 788 [25,0\%] pacientes no braço de tratamento usual; razão de taxa, 1,09; 95\% intervalo de confiança [IC], 0,96-1,23; P = 0,18). A utilização de Hidroxicloroquina foi associada a um tempo mais longo até a alta com vida do hospital, quando comparado ao tratamento usual (mediana de 16 dias vs. 13 dias), além disso, há uma menor probabilidade de alta com vida em 28 dias (razão de taxas de 0,92, IC de 95\% 0,85 a 0,99) (The RECOVERY Collaborative Group, 2020).

Em 4 de junho de 2020, em resposta a um pedido da MHRA (do inglês, Medicines \& Healthcare products Regulatory 
Agency), o comitê que realiza o monitoramento de dados independente conduziu uma revisão dos dados e recomendou que os investigadores principais do estudo RECOVERY revisassem os dados não cegos sobre o braço da Hidroxicloroquina do estudo. Os investigadores principais e o julgamento do Comitê Diretor concluíram que os dados não mostraram nenhum efeito benéfico da Hidroxicloroquina em pacientes hospitalizados com COVID-19. Portanto, a inscrição de participantes para o braço de Hidroxicloroquina para esse estudo foi fechado em 5 de junho de 2020 e o resultado preliminar foi tornado público. Os investigadores orientaram que qualquer paciente que estivesse em uso da Hidroxicloroquina como parte do estudo deveria interromper o tratamento, e a OMS aceitou a recomendação do Comitê Diretor Internacional do estudo RECOVERY, parando no dia 25 de julho os estudos com a Hidroxicloroquina para o tratamento da COVID-19 (The RECOVERY Collaborative Group, 2020)

No dia 15 de outubro de 2020, foram liberados os resultados prévios do ensaio clínico terapêutico randomizado SOLIDARITY, coordenado pela Organização Mundial da Saúde, focado na eficácia do uso terapêutico dos medicamentos readaptados para o tratamento de COVID-19 (WHO Solidarity trial consortium, 2021).

O estudo também não encontrou nenhuma evidência definitiva de benefício com o uso da Hidroxicloroquina, concluindo que essa droga possui pouco ou nenhum efeito na mortalidade em 28 dias ou no curso hospitalar de pacientes hospitalizados com COVID-19. Além disso, afirmou não ter conseguido identificar perigo específico em seu uso em qualquer subgrupo de pacientes (WHO Solidarity trial consortium, 2021).

Desta forma, os resultados encontrados pelo RECOVERY e o SOLIDARITY corroboram que a utilização da Hidroxicloroquina para tratar os pacientes com COVID-19 não oferece nenhum benefício clínico ao paciente (WHO Solidarity trial consortium, 2021).

\section{Considerações Finais}

Na pandemia da COVID-19 utilizou-se resultados de estudos in vitro e in vivo para avaliar o curso e evolução da doença, principalmente na busca de possíveis terapias farmacológicas eficazes, visto a inexistência de uma diretriz préestabelecida para o tratamento dessa nova infecção viral.

Ao analisar os estudos in vitro, pode-se destacar como pontos positivos a rapidez com que normalmente são realizados, a especificidade, o menor custo, o maior controle de variáveis, maior reprodutibilidade dos resultados e facilidade de mapear os mecanismos de ação dos fármacos. Diante disso, foi o modelo de estudo mais utilizado durante o início da pandemia.

Já os estudos in vivo, possuem melhor capacidade de simular uma condição fisiológica, projetar o perfil farmacológico, definir o perfil toxicológico e possíveis efeitos colaterais. No entanto, seus resultados começaram a ser publicados mais tardiamente, visto que dependem de um acompanhamento longitudinal para gerar desfechos confiáveis.

Com isso, os primeiros estudos publicados testaram vários medicamentos desenvolvidos para outras patologias, sendo que tais estudos mostraram resultados promissores contra a SARS-CoV-2 in vitro (Liu et al., 2020; Yao et al., 2020). Tais estudos promoveram investigações no uso off-label desses medicamentos, incluindo o antimalárico Hidroxicloroquina (HCQ), apesar das falhas e o risco de viés.

Apesar de os resultados preliminares in vitro terem se mostrado positivos e promissores, as evidências de ensaios clínicos randomizados apontaram que a Hidroxicloroquina não provocou os mesmos efeitos in vivo contra a COVID-19. Os estudos não encontraram evidências de que a Hidroxicloroquina ajudasse na recuperação de infectados e nem de que a droga prevenisse pessoas saudáveis de contrair o vírus (The RECOVERY Collaborative Group, 2020).

A OMS aceitou, no dia 25 de Julho de 2020, a recomendação que foi feita no dia 5 de julho de 2020 pelo Comitê Diretor Internacional do estudo RECOVERY para interromper os estudos com a Hidroxicloroquina para o tratamento da 
COVID-19.

Desta forma, este presente trabalho reforça a importância das etapas da pesquisa cientifica, e que novos trabalhos possam ser desenvolvidos com o intuito de validar os achados publicados na literatura científica, com o intuito de garantir a total eficácia e segurança do medicamento.

\section{Referências}

Abella, B. S., Jolkovsky, E. L., Biney, B. T., Uspal, J. E., Hyman, M. C., Frank, I., Hensley, S. E., Gill, S., Vogl, D. T., Maillard, I., Babushok, D. V., Huang, A. C., Nasta, S. D., Walsh, J. C., Wiletyo, E. P., Gimotty, P. A., Milone, M. C., \& Amaravadi, R. K. (2021). Efficacy and Safety of Hydroxychloroquine vs Placebo for Pre-exposure SARS-CoV-2 Prophylaxis Among Health Care Workers. JAMA Internal Medicine, 181(2), 195. https://doi.org/10.1001/jamainternmed.2020.6319

Agostini, M. L., Andres, E. L., Sims, A. C., Graham, R. L., Sheahan, T. P., Lu, X., Smith, E. C., Case, J. B., Feng, J. Y., Jordan, R., Ray, A. S., Cihlar, T., Siegel, D., Mackman, R. L., Clarke, M. O., Baric, R. S., \& Denison, M. R. (2018). Coronavirus Susceptibility to the Antiviral Remdesivir (GS-5734) Is Mediated by the Viral Polymerase and the Proofreading Exoribonuclease. MBio, 9(2). https://doi.org/10.1128/mBio.00221-18

Andrade, K. R. C. de, Carvalho, V. K. da S., Farinasso, C. M., Lima, A. A. de, Silva, R. B., Wachira, V. K., Capucho, H. C., Souza, P. M. de, Vanni, T., Sachetti, C. G., \& Rêgo, D. F. (2020). Terapia medicamentosa para infecções por coronavírus em humanos: revisão sistemática rápida. Ciência \& Saúde Coletiva, 25(9), 3517-3554. https://doi.org/10.1590/1413-81232020259.14242020

Ben-Zvi, I., Kivity, S., Langevitz, P., \& Shoenfeld, Y. (2012). Hydroxychloroquine: From Malaria to Autoimmunity. Clinical Reviews in Allergy \& Immunology, 42(2), 145-153. https://doi.org/10.1007/s12016-010-8243-X

Bortoli, R., \& Santiago, M. (2007). Chloroquine ototoxicity. Clinical Rheumatology, 26(11), 1809-1810. https://doi.org/10.1007/s10067-007-0662-6

Boulware, D. R., Pullen, M. F., Bangdiwala, A. S., Pastick, K. A., Lofgren, S. M., Okafor, E. C., Skipper, C. P., Nascene, A. A., Nicol, M. R., Abassi, M., Engen, N. W., Cheng, M. P., LaBar, D., Lother, S. A., MacKenzie, L. J., Drobot, G., Marten, N., Zarychanski, R., Kelly, L. E., ... Hullsiek, K. H. (2020). A Randomized Trial of Hydroxychloroquine as Postexposure Prophylaxis for Covid-19. New England Journal of Medicine, 383(6), 517-525. https://doi.org/10.1056/NEJMoa2016638

Brunton, L. L., Hidal-Dandan, R., \& Knollmann, B. C. (2019). As bases farmacológicas da terapêutica de Goodman \& Gilman. In Artmed (13ª).

Caly, L., Druce, J. D., Catton, M. G., Jans, D. A., \& Wagstaff, K. M. (2020). The FDA-approved drug ivermectin inhibits the replication of SARS-CoV-2 in vitro. Antiviral Research, 178, 104787. https://doi.org/10.1016/j.antiviral.2020.104787

Chen, C., Zhang, Y., Huang, J., Yin, P., Cheng, Z., Wu, J., Chen, S., Zhang, Y., Chen, B., Lu, M., Luo, Y., Ju, L., Zhang, J., \& Wang, X. (2020). Favipiravir versus Arbidol for COVID-19: A Randomized Clinical Trial. MedRxiv, 2020.03.17.20037432. https://doi.org/10.1101/2020.03.17.20037432

Cortegiani, A., Ingoglia, G., Ippolito, M., Giarratano, A., \& Einav, S. (2020). A systematic review on the efficacy and safety of chloroquine for the treatment of COVID-19. Journal of Critical Care, 57, 279-283. https://doi.org/10.1016/j.jcrc.2020.03.005

Estrela, C. (2018). Metodologia Científica: Ciência, Ensino, Pesquisa (Artes Médicas (Ed.).

Fiocruz. (2021). Boletim observatório COVID-19 - Semanas epidemiológicas 10 e 11. Observatório Covid-19/Fiocruz, 7-20/3/21.

Furtado, R. H. M., Berwanger, O., Fonseca, H. A., Corrêa, T. D., Ferraz, L. R., Lapa, M. G., Zampieri, F. G., Veiga, V. C., Azevedo, L. C. P., Rosa, R. G., Lopes, R. D., Avezum, A., Manoel, A. L. O., Piza, F. M. T., Martins, P. A., Lisboa, T. C., Pereira, A. J., Olivato, G. B., Dantas, V. C. S., ... Cavalcanti, A. B. (2020). Azithromycin in addition to standard of care versus standard of care alone in the treatment of patients admitted to the hospital with severe COVID-19 in Brazil (COALITION II): a randomised clinical trial. The Lancet, 396(10256), 959-967. https://doi.org/10.1016/S0140-6736(20)31862-6

Furuta, Y., Komeno, T., \& Nakamura, T. (2017). Favipiravir (T-705), a broad spectrum inhibitor of viral RNA polymerase. Proceedings of the Japan Academy, Series B, 93(7), 449-463. https://doi.org/10.2183/pjab.93.027

Gautret, P., Lagier, J.-C., Parola, P., Hoang, V. T., Meddeb, L., Mailhe, M., Doudier, B., Courjon, J., Giordanengo, V., Vieira, V. E., Tissot Dupont, H., Honoré, S., Colson, P., Chabrière, E., La Scola, B., Rolain, J.-M., Brouqui, P., \& Raoult, D. (2020). Hydroxychloroquine and azithromycin as a treatment of COVID-19: results of an open-label non-randomized clinical trial. International Journal of Antimicrobial Agents, 56(1), 105949. https://doi.org/10.1016/j.ijantimicag.2020.105949

Goldman, F. D., Gilman, A. L., Hollenback, C., Kato, R. M., Premack, B. A., \& Rawlings, D. J. (2000). Hydroxychloroquine inhibits calcium signals in T cells: a new mechanism to explain its immunomodulatory properties. Blood, 95(11), 3460-3466. http://www.ncbi.nlm.nih.gov/pubmed/10828029

Iser, B. P. M., Sliva, I., Raymundo, V. T., Poleto, M. B., Schuelter-Trevisol, F., \& Bobinski, F. (2020). Suspected COVID-19 case definition: a narrative review of the most frequent signs and symptoms among confirmed cases. Epidemiologia e Serviços de Saúde, 29(3). https://doi.org/10.5123/S167949742020000300018

Jia, H. P., Look, D. C., Shi, L., Hickey, M., Pewe, L., Netland, J., Farzan, M., Wohlford-Lenane, C., Perlman, S., \& McCray, P. B. (2005). ACE2 Receptor Expression and Severe Acute Respiratory Syndrome Coronavirus Infection Depend on Differentiation of Human Airway Epithelia. Journal of Virology, 79(23), 14614-14621. https://doi.org/10.1128/JVI.79.23.14614-14621.2005

Jose, R. J., \& Manuel, A. (2020). COVID-19 cytokine storm: the interplay between inflammation and coagulation. The Lancet Respiratory Medicine, 8(6), e46-e47. https://doi.org/10.1016/S2213-2600(20)30216-2 
Kawai, T., \& Akira, S. (2010). The role of pattern-recognition receptors in innate immunity: update on Toll-like receptors. Nature Immunology, 11(5), 373384. https://doi.org/10.1038/ni.1863

Keyaerts, E., Vijgen, L., Maes, P., Neyts, J., \& Ranst, M. Van. (2004). In vitro inhibition of severe acute respiratory syndrome coronavirus by chloroquine. Biochemical and Biophysical Research Communications, 323(1), 264-268. https://doi.org/10.1016/j.bbrc.2004.08.085

Ko, J. Y., Danielson, M. L., Town, M., Derado, G., Greenlund, K. J., Kirley, P. D., Alden, N. B., Yousey-Hindes, K., Anderson, E. J., Ryan, P. A., Kim, S., Lynfield, R., Torres, S. M., Barney, G. R., Bennett, N. M., Sutton, M., Talbot, H. K., Hill, M., Hall, A. J., \& George, A. (2020). Risk Factors for Coronavirus Disease 2019 (COVID-19)-Associated Hospitalization: COVID-19-Associated Hospitalization Surveillance Network and Behavioral Risk Factor Surveillance System. Clinical Infectious Diseases. https://doi.org/10.1093/cid/ciaa1419

Kumar, M., Taki, K., Gahlot, R., Sharma, A., \& Dhangar, K. (2020). A chronicle of SARS-CoV-2: Part-I - Epidemiology, diagnosis, prognosis, transmission and treatment. Science of The Total Environment, 734, 139278. https://doi.org/10.1016/j.scitotenv.2020.139278

Lagneaux, L., Delforge, A., Carlier, S., Massy, M., Bernier, M., \& Bron, D. (2001). Early induction of apoptosis in B-chronic lymphocytic leukaemia cells by hydroxychloroquine: activation of caspase-3 and no protection by survival factors. British Journal of Haematology, 112(2), 344-352. https://doi.org/10.1046/j.1365-2141.2001.02553.x

Lee, T. C., MacKenzie, L. J., McDonald, E. G., \& Tong, S. Y. C. (2020). An observational cohort study of hydroxychloroquine and azithromycin for COVID19: (Can’t Get No) Satisfaction. International Journal of Infectious Diseases, 98, 216-217. https://doi.org/10.1016/j.ijid.2020.06.095

Lima, C. M. A. de O. (2020). Information about the new coronavirus disease (COVID-19). Radiologia Brasileira, 53(2), V-VI. https://doi.org/10.1590/01003984.2020.53.2e1

Liu, J., Cao, R., Xu, M., Wang, X., Zhang, H., Hu, H., Li, Y., Hu, Z., Zhong, W., \& Wang, M. (2020). Hydroxychloroquine, a less toxic derivative of chloroquine, is effective in inhibiting SARS-CoV-2 infection in vitro. Cell Discovery, 6(1), 6-9. https://doi.org/10.1038/s41421-020-0156-0

Maisonnasse, P., Guedj, J., Contreras, V., Behillil, S., Solas, C., Marlin, R., Naninck, T., Pizzorno, A., Lemaitre, J., Gonçalves, A., Kahlaoui, N., Terrier, O., Fang, R. H. T., Enouf, V., Dereuddre-Bosquet, N., Brisebarre, A., Touret, F., Chapon, C., Hoen, B., \& Le Grand, R. (2020). Hydroxychloroquine use against SARS-CoV-2 infection in non-human primates. Nature. https://doi.org/10.1038/s41586-020-2558-4

Manohar, S., Tripathi, M., \& Rawat, D. (2014). 4-Aminoquinoline Based Molecular Hybrids as Antimalarials: An Overview. Current Topics in Medicinal Chemistry, 14(14), 1706-1733. https://doi.org/10.2174/1568026614666140808125728

Mansilla, E., Marin, G. H., Nuñez, L., Drago, H., Sturla, F., Mertz, C., Rivera, L., Ichim, T., Riordan, N., \& Raimondi, C. (2010). The Lysosomotropic Agent, Hydroxychloroquine, Delivered in a Biodegradable Nanoparticle System, Overcomes Drug Resistance of B-Chronic Lymphocytic Leukemia Cells In Vitro. Cancer Biotherapy and Radiopharmaceuticals, 25(1), 97-103. https://doi.org/10.1089/cbr.2009.0655

Martinez, M. A. (2020). Compounds with Therapeutic Potential against Novel Respiratory 2019 Coronavirus. Antimicrobial Agents and Chemotherapy, 64(5). https://doi.org/10.1128/AAC.00399-20

Mates, M., Nesher, G., \& Zevin, S. (2007). Quinines--past and present. Harefuah, 146(7), 560-562, 572. http://www.ncbi.nlm.nih.gov/pubmed/17803173

Mauthe, M., Orhon, I., Rocchi, C., Zhou, X., Luhr, M., Hijlkema, K.-J., Coppes, R. P., Engedal, N., Mari, M., \& Reggiori, F. (2018). Chloroquine inhibits autophagic flux by decreasing autophagosome-lysosome fusion. Autophagy, 14(8), 1435-1455. https://doi.org/10.1080/15548627.2018.1474314

Mehta, P., McAuley, D. F., Brown, M., Sanchez, E., Tattersall, R. S., \& Manson, J. J. (2020). COVID-19: consider cytokine storm syndromes and immunosuppression. The Lancet, 395(10229), 1033-1034. https://doi.org/10.1016/S0140-6736(20)30628-0

Ministerio da Saúde. (2021). Painel Coronavirus. https://covid.saude.gov.br/

Ministério da Saúde. (2020). Ministério da Saúde amplia orientações para uso de Cloroquina. https://www.gov.br/saude/pt-br/assuntos/noticias/ministerio-dasaude-amplia-orientacoes-para-uso-da-cloroquina-2

Mitjà, O., \& Clotet, B. (2020). Use of antiviral drugs to reduce COVID-19 transmission. The Lancet Global Health, 8(5), e639-e640. https://doi.org/10.1016/S2214-109X(20)30114-5

Nosál, R., Jančinová, V., \& Petríková, M. (1995). Chloroquine inhibits stimulated platelets at the arachidonic acid pathway. Thrombosis Research, 77(6), 531542. https://doi.org/10.1016/0049-3848(95)00028-3

Oliveira, W. K. de, Duarte, E., França, G. V. A. de, \& Garcia, L. P. (2020). Como o Brasil pode deter a COVID-19. Epidemiologia e Serviços de Saúde, 29. https://doi.org/10.5123/S1679-49742020000200023

Organização Pan-Americana da Saúde. (2020). Folha Informativa Covid-19 - Escritório Da OPAS E Da OMS No Brasil. https://www.paho.org/pt/COVID19

Page, F. (1951). treatment of lupus erythematosus with mepacrine. The Lancet, 258(6687), 755-758. https://doi.org/10.1016/S0140-6736(51)91643-1

Pereira, A. S., Shitsuka, D. M., Parreira, F. J., \& Shitsuka, R. (2018). Metodologia da pesquisa científica (N. UFSM (Ed.); $1^{\mathrm{a}}$ ).

Rainsford, K. D., Parke, A. L., Clifford-Rashotte, M., \& Kean, W. F. (2015). Therapy and pharmacological properties of hydroxychloroquine and chloroquine in treatment of systemic lupus erythematosus, rheumatoid arthritis and related diseases. Inflammopharmacology, 23(5), 231-269. https://doi.org/10.1007/s10787-015-0239-y

Rempenault, C., Combe, B., Barnetche, T., Gaujoux-Viala, C., Lukas, C., Morel, J., \& Hua, C. (2018). Metabolic and cardiovascular benefits of hydroxychloroquine in patients with rheumatoid arthritis: a systematic review and meta-analysis. Annals of the Rheumatic Diseases, 77(1), 98-103. https://doi.org/10.1136/annrheumdis-2017-211836 
Retallack, H., Di Lullo, E., Arias, C., Knopp, K. A., Laurie, M. T., Sandoval-Espinosa, C., Mancia Leon, W. R., Krencik, R., Ullian, E. M., Spatazza, J., Pollen, A. A., Mandel-Brehm, C., Nowakowski, T. J., Kriegstein, A. R., \& DeRisi, J. L. (2016). Zika virus cell tropism in the developing human brain and inhibition by azithromycin. Proceedings of the National Academy of Sciences, 113(50), 14408-14413. https://doi.org/10.1073/pnas.1618029113

Rolain, J.-M., Colson, P., \& Raoult, D. (2007). Recycling of chloroquine and its hydroxyl analogue to face bacterial, fungal and viral infections in the 21st century. International Journal of Antimicrobial Agents, 30(4), 297-308. https://doi.org/10.1016/j.ijantimicag.2007.05.015

Rynes, R. I., \& Bernstein, H. N. (1993). Ophthalmologic safety profile of antimalarial drugs. Lupus, 2 Suppl 1, S17-9. http://www.ncbi.nlm.nih.gov/pubmed/8485566

Schrezenmeier, E., \& Dörner, T. (2020). Mechanisms of action of hydroxychloroquine and chloroquine: implications for rheumatology. Nature Reviews Rheumatology, 16(3), 155-166. https://doi.org/10.1038/s41584-020-0372-x

Sheahan, T. P., Sims, A. C., Leist, S. R., Schäfer, A., Won, J., Brown, A. J., Montgomery, S. A., Hogg, A., Babusis, D., Clarke, M. O., Spahn, J. E., Bauer, L., Sellers, S., Porter, D., Feng, J. Y., Cihlar, T., Jordan, R., Denison, M. R., \& Baric, R. S. (2020). Comparative therapeutic efficacy of remdesivir and combination lopinavir, ritonavir, and interferon beta against MERS-CoV. Nature Communications, 11(1), 222. https://doi.org/10.1038/s41467-019-13940-6

Skipper, C. P., Pastick, K. A., Engen, N. W., Bangdiwala, A. S., Abassi, M., Lofgren, S. M., Williams, D. A., Okafor, E. C., Pullen, M. F., Nicol, M. R., Nascene, A. A., Hullsiek, K. H., Cheng, M. P., Luke, D., Lother, S. A., MacKenzie, L. J., Drobot, G., Kelly, L. E., Schwartz, I. S., \& Boulware, D. R. (2020). Hydroxychloroquine in Nonhospitalized Adults With Early COVID-19. Annals of Internal Medicine, 173(8), 623-631. https://doi.org/10.7326/M20-4207

Tang, W., Cao, Z., Han, M., Wang, Z., Chen, J., Sun, W., Wu, Y., Xiao, W., Liu, S., Chen, E., Chen, W., Wang, X., Yang, J., Lin, J., Zhao, Q., Yan, Y., Xie, Z., Li, D., Yang, Y., \& Xie, Q. (2020). Hydroxychloroquine in patients with mainly mild to moderate coronavirus disease 2019: open label, randomised controlled trial. BMJ, m1849. https://doi.org/10.1136/bmj.m1849

Tett, S., Cutler, D., Day, R., \& Brown, K. (1989). Bioavailability of hydroxychloroquine tablets in healthy volunteers. British Journal of Clinical Pharmacology, 27(6), 771-779. https://doi.org/10.1111/j.1365-2125.1989.tb03439.x

The RECOVERY Collaborative Group. (2020). Effect of Hydroxychloroquine in Hospitalized Patients with Covid-19. New England Journal of Medicine, 383(21), 2030-2040. https://doi.org/10.1056/NEJMoa2022926

Wang, M., Cao, R., Zhang, L., Yang, X., Liu, J., Xu, M., Shi, Z., Hu, Z., Zhong, W., \& Xiao, G. (2020). Remdesivir and chloroquine effectively inhibit the recently emerged novel coronavirus (2019-nCoV) in vitro. Cell Research, 30(3), 269-271. https://doi.org/10.1038/s41422-020-0282-0

WHO Solidarity trial consortium. (2021). Repurposed Antiviral Drugs for Covid-19 — Interim WHO Solidarity Trial Results. New England Journal of Medicine, 384(6), 497-511. https://doi.org/https://doi.org/10.1101/2020.10.15.20209817

Winkler, E. S., Bailey, A. L., Kafai, N. M., Nair, S., McCune, B. T., Yu, J., Fox, J. M., Chen, R. E., Earnest, J. T., Keeler, S. P., Ritter, J. H., Kang, L.-I., Dort, S., Robichaud, A., Head, R., Holtzman, M. J., \& Diamond, M. S. (2020). SARS-CoV-2 infection of human ACE2-transgenic mice causes severe lung inflammation and impaired function. Nature Immunology, 21(11), 1327-1335. https://doi.org/10.1038/s41590-020-0778-2

Wolfe, F., \& Marmor, M. F. (2010). Rates and predictors of hydroxychloroquine retinal toxicity in patients with rheumatoid arthritis and systemic lupus erythematosus. Arthritis Care \& Research, 62(6), 775-784. https://doi.org/10.1002/acr.20133

World Health Organization. (2021). Who Coronavirus Disease (COVID-19) DASHBOARD.

Xavier, A. R., Silva, J. S., Almeida, J. P. C. L., Conceição, J. F. F., Lacerda, G. S., \& Kanaan, S. (2020). COVID-19: clinical and laboratory manifestations in novel coronavirus infection. Jornal Brasileiro de Patologia e Medicina Laboratorial, 56. https://doi.org/10.5935/1676-2444.20200049

Xia, S., Zhu, Y., Liu, M., Lan, Q., Xu, W., Wu, Y., Ying, T., Liu, S., Shi, Z., Jiang, S., \& Lu, L. (2020). Fusion mechanism of 2019-nCoV and fusion inhibitors targeting HR1 domain in spike protein. Cellular \& Molecular Immunology, 17(7), 765-767. https://doi.org/10.1038/s41423-020-0374-2

Yao, X., Ye, F., Zhang, M., Cui, C., Huang, B., Niu, P., Liu, X., Zhao, L., Dong, E., Song, C., Zhan, S., Lu, R., Li, H., Tan, W., \& Liu, D. (2020). In Vitro Antiviral Activity and Projection of Optimized Dosing Design of Hydroxychloroquine for the Treatment of Severe Acute Respiratory Syndrome Coronavirus 2 (SARS-CoV-2). Clinical Infectious Diseases, 71(15), 732-739. https://doi.org/10.1093/cid/ciaa237

Zhang, X., Wu, J., Du, F., Xu, H., Sun, L., Chen, Z., Brautigam, C. A., Zhang, X., \& Chen, Z. J. (2014). The Cytosolic DNA Sensor cGAS Forms an Oligomeric Complex with DNA and Undergoes Switch-like Conformational Changes in the Activation Loop. Cell Reports, 6(3), 421-430. https://doi.org/10.1016/j.celrep.2014.01.003

Zhou, Q., McCracken, M. A., \& Strobl, J. S. (2002). Control of Mammary Tumor Cell Growth in Vitro by Novel Cell Differentiation and Apoptosis Agents. Breast Cancer Research and Treatment, 75(2), 107-117. https://doi.org/10.1023/A:1019698807564

Zimmermann, P., Ziesenitz, V. C., Curtis, N., \& Ritz, N. (2018). The Immunomodulatory Effects of Macrolides-A Systematic Review of the Underlying Mechanisms. Frontiers in Immunology, 9. https://doi.org/10.3389/fimmu.2018.00302 